\title{
Study on the Creation of Chinese Main Theme Documentaries in the New Period*
}

\author{
Yanyan Bai \\ Zaozhuang University \\ Zaozhuang, China
}

\begin{abstract}
In the past two years, the development of China's documentary industry has been booming, especially the main theme documentary has opened up a new world. A large number of new theme documentaries with good communication and social benefits have begun to enter the audience's field of vision, and their creative ideas and expression techniques are also different. In the context of social media in the new era, there is not much research literature on the new forms, new expressions and new approaches of the main theme documentaries. This article elaborates from the analysis of the creative characteristics of the main theme documentary in the new period, the elaboration of the operating strategy of the main theme documentary in the new period, and the development of the main theme Chinese documentary.
\end{abstract}

Keywords—new period; theme documentary; creation

\section{INTRODUCTION}

On October 18, 2017, the 19th National Congress of the Communist Party of China was held in Beijing. This is the most important event in the political life of Chinese citizens in 2017. Since then, socialism with Chinese characteristics has entered a new era. Around the 19th CPC National Congress, CCTV broadcast a number of TV documentaries in line with the theme of the times. In 2018, there are many important publicity nodes to celebrate the 90th anniversary of the founding of the army and the 40th anniversary of reform and opening up, and a number of outstanding themes that reflect the style of the new era continue to emerge, such as "China Reinvents Itself", "My Youth on the Belt and Road" and so on. In 2019, in order to celebrate the 70th anniversary of the founding of the People's Republic of China, a large-scale documentary film "We Walk on the Boulevard" shows the great journey of New China in a panoramic view. At the key historical node of the great rejuvenation of the Chinese nation, documentaries can tell Chinese stories well and sound Chinese. Taking documentary as the carrier of thought and culture and promoting the exchange and mutual learning of human civilization is the goal and development direction of Chinese documentary in the new era. With the development of the times, the creative ideas and expression methods of the main theme documentary in China have changed dramatically. The main theme documentary has the responsibility to pay

*Project: This article is the research result of the Shandong Province Arts Science Key Project in 2019, "Study on the Creation of Chinese Main Theme Documentaries in the New Period" (Project No.: QN201906051). attention to social change, promote the mainstream ideology, study the narrative strategy and expression methods of the main theme documentary, and explore how to make it acceptable and generate recognition and reflection. This is of great significance to the creation and development of the main theme documentary.

\section{THE MAIN THEME DOCUMENTARY OF THE NEW ERA}

The theme documentary is a documentary image that can highlight the main theme of the times, reflect the characteristics of the times, reflect the new features of the times, and show the achievements of the country. For a long time in the 20th century, the basic principle and core concept that guided the creation of Chinese documentaries was "propaganda and education." With the entering of a new era of socialism with Chinese characteristics, the Chinese film and television industry has also entered a new development period. In particular, the main theme documentary gradually got rid of the pure political education in the 1980s and 1990s, and began to try many ways in creation, seeking political, commercial and artistic balance. Different from traditional theme melody documentaries, the theme documentary in the new era carry the spirit of the new era of China with a wider range of themes, more diversified narratives, and more diverse forms of video expression. While telling the Chinese story, it also gives full play to its ideological value and influence. For example, "Innovative China", from life science and technology, new energy to manufacturing in big countries, it tells everyone the rapid development of science and technology in the motherland with live and true stories, and is regarded as "selfexpanding series" by all netizens. "Xi Jinping's Strategy for Governing the Country: China in the Past Five Years" uses the three themes of "people's feelings", "big country governance", and "win-win cooperation" to focus on the development and changes of Chinese society, and in-depth interpretation of China's development path, development concept and inspiration to the world . "My Youth on the Belt and Road" focuses on the stories of young people who are sweating and dreaming about youth in countries along "the Belt and Road".

\section{ANALYSIS OF THE CREATIVE CHARACTERISTICS OF THEME DOCUMENTARY IN THE NEW PERIOD}

The creation of theme documentary in the new period shows a trend of diversified development. The creative methods and performance techniques are constantly innovated, 
the Lanzhou Campaign, laying a solid foundation for the liberation of the Northwest. However, instead of writing the war from the standpoint of the victor, this documentary shows people the trauma that war has brought to experienced persons. This narrative position no longer praises the lofty and greatness of this just war, nor does it try to render the grand situation after the liberation of Lanzhou, but instead emphasizes the psychological sorrow of living people. The 32nd regiment surveyor and mapper Yang Xinglong recalled: "After the battle, we regiment lived to the common people's house, and cookhouse made people some noodles. The correspondent filled a pot of noodles, and there was no one to cook rice. The army was very sad. Living people were really hard. "There is no elation of the victor here, and the sentimentality of the veterans is always important in the narrative. With the peaceful liberation of Xining and Xinjiang, the documentary film's performance of war trauma has been directly transformed into a yearning for peace, which is rare in the main theme documentary narration. "Decisive Battle Lanzhou" shows this great pattern of avoiding war and the beauty of human nature.

\section{The Way of Expression Is High-tech}

In terms of audiovisual presentation, in addition to conventional lens movements such as push, pull, shake, move, follow, change, and mix, a large number of aerial view angles and wide-angle lenses of the aerial camera are also used. The aerial lens brings a macro and comprehensive perspective to show the magnificent momentum and scene. In the first episode of the eighth season of "My Youth on the Belt and Road," in order to express the Nooro CSP project, a combination of time-lapse photography, aerial photography, and up- and down-grade lenses was used, fully reflecting the scale and momentum of the world's largest CSP plant under construction. In the third episode of "Smart China", "Forward Wisdom", a lot of CG animation forms have been adopted to demonstrate that CRRC Zhuji Group has adopted the world's leading high-speed rail technology. "China Reinvents Itself" uses artificial intelligence to simulate human voice to complete the dubbing, and uses artificial intelligence technology to synthesize, making all the sound clips appearing in the entire documentary extremely real. This combination not only shows China's brilliant achievements in artificial intelligence, but also broadens new forms of documentary creation, which itself is the best interpretation of the spirit of innovation.

\section{THE Popular Operation STRATEGy OF THE THEME DOCUMENTARY IN THE NEW PERIOD}

Theme documentary has always been an elite production method, and the communication channels are from top to bottom. The general public has few opportunities to participate in content production. With the development of social media and the rise of participatory culture, the existence of documentaries has changed. The theme documentary is also more grounded and popular because of the participation of the whole people. 
the Chinese Communist Party's determination to fight

\section{A. Cinema Chain: Theme Documentary Becomes a New} Force

Since the State Administration of Radio, Film and Television issued a policy to promote the development of documentaries in 2010, documentaries are no longer confined to the television field, but have begun to appear on the big screen in the form of documentary films and appear in the audience's sight. Then they went through five years of "adversity", and the film often went unnoticed. Due to the relatively serious content and the fact that the main features of documentary images are relatively simple, the box office performance of documentary films has not seen any improvement. In the past two years, the "poor brothers" documentary, previously known as television, has finally been recognized by the theater market. The good business performance has given the commercial potential of the theme documentary more imagination. In 2017, the documentary "Twenty-two" achieved 170 million box offices, breaking the box office record of the documentary film. In 2018, the largescale political commentary film "Amazing China" with the theme of "Strengthening" entered the cinema, and with a box office record of 480 million, it created a box office record for cinema documentaries. It has aroused widespread concern in society and has become a phenomenon-level public opinion hotspot, which has played a prelude to the arrival of a new era.

\section{B. New Media: The Main Melody Documentary Becomes a New Influencer}

The advent of the new media era has brought new opportunities to the development of documentaries, greatly expanding the industrial space and channels for documentaries, and breaking the cycle restrictions of traditional documentaries broadcast on television or theaters. In the Internet era, network channels have lowered the threshold for documentary film spread and expanded the breadth and depth of spread. Mainstream video websites such as iQiyi, Tencent and Youku not only opened up documentary sections, but also actively participated in the production of documentary works. The implementation of cross-border communication has made video websites a new way of broadcasting. In 2017, four of the top five documentary video hits on the Internet were the main melody and political documentary, and the top one was "Splendid China".

\section{Multi-screen Interaction: Social Media Has Become an Important Means of Communication}

In the era of new media, documentaries put aside their past high-cold status and become the new "internet celebrity". Not only has it appeared on Internet social platforms for a long time, it has also become a network issue, and it has also successfully entered the barrage website that teenagers love. The audience used the new media to express their views through messages and barrage, and their personal voice and emotions were expressed. In addition to "short and beautiful" documentaries, mainstream documentaries have also become popular online. This kind of film is generally premiered on television media, which ignites the topic on the Internet, and then triggers the return of users to watch in new media. Introduced in 2017, the "Sword of Inspection" demonstrated corruption and aroused praise on the internet.

Comments on social media such as WeChat and Weibo, and recommendations from "internet celebrity" can effectively increase documentary exposure. The user's real perception experience can bring infectious communication effects. During the broadcast of Splendid China, the slogan "Amazing China" spread throughout the country. Based on this topic, a successful online and offline documentary "marketing" was explored. The single-direction dissemination was changed to ecological transmission. Through the interaction of the whole people, the distance between the documentary and the audience was narrowed. "Amazing China" has become a buzzword and word-formation. Behind the language is the plainest expression of public opinion.

\section{THE DEVELOPMENT TREND OF CHINESE DOCUMENTARIES UNDER THE THEME OF THE TIMES}

\section{A. Continuing to Play the Role of Mainstream Media, Strengthening Company Guidance, and Valuing Personal Production}

As the core force of theme documentary production, the mainstream media should unite and cooperate with each other. The government should build a mainstream media platform to break the situation of mainstream media's own production, and let everyone cooperate with each other, improve the utilization of documentary resources, and focus on developing the main theme documentary. The mainstream media should change their creative concepts, establish new creative ideas, cater to the audience's aesthetic tastes, involve the audience in the process of selecting topics and materials for the program, and enhance their awareness of participation.

The film and television company is an important force in the production of theme documentary and plays an important role in the development of theme documentary. Film and television companies must establish the correct concept of interests, respect the theme documentary, and consciously participate in the production of documentaries. The government can increase financial support for film and television companies through policies, enhance the production enthusiasm of film and television companies, regulate the creation of film and television companies, and use laws and regulations to guide film and television companies to produce theme documentary and promote the development of film and television company production capabilities.

In the current era, self-media has become a new type of communication. Individually produced documentaries can be spread to a wider range through self-media platforms. Compared with mainstream media, individual producers are more able to integrate into the life of the masses, and are more able to choose topics related to life, so they are more popular with audiences. The government must attach importance to personal creation, set outstanding documentary works in personal creation as typical, and guide individual producers to choose suitable themes and produce high-quality theme documentaries, contributing to the development of theme 
documentary and promote the progress of China's documentary career.

\section{B. Enhancing Marketing and Communication Ideas}

Theme documentary should have not only cultural value but also commercial value. Against the backdrop of hitting 60 billion annual box offices in 2018, there are only 13 domestic documentaries on the upper circuit. Among them, the highest box office was 480 million of "Amazing China", and most of the rest were hundreds of thousands of box office. Having a good reputation but not a good box office has become a big dilemma for the survival and development of domestic documentaries. The low cinema rankings, the audience's tendency to choose cinemas, and the practical difficulties of documentary creators are all reasons why documentaries have a good reputation but not a good box office. The cultural or propaganda department can organize a documentary contest to promote multiple media, dig out outstanding domestically produced documentaries, buy copyrights and push them online and on TV. For some directors with financial difficulties, they can choose to sign and buy in advance. Provide them with some financial support to help them create. In this way, it can not only meet the needs of the people, but also allow more documentary creators to keep their ingenuity and feelings and bring more fine works.

In addition, there is the rise of "Over the Top" family viewing. According to research, the user viewing ports of Tencent, iQiyi and Youku are mainly mobile clients, followed by OTT. Technological development, speed upgrade of the network and popularization of terminals have jointly promoted the growth of OTT users, and the "family watching" trend of documentaries is quietly rising. Compared with the mobile terminal and the PC terminal, the OTT terminal has its unique advantages. On the one hand, the large screen on the OTT side brings a good look and feel, on the other hand, the OTT terminal returns to the traditional home viewing environment, allowing family members to cultivate and interact with each other during the viewing process, receiving user favor. Documentary film users have begun to take shape on the OTT client "CIBN Cool Meow" built by Youku with CIBN Internet TV.

\section{Mini-documentary: Publicity Based on "Short" Form}

Tsinghua University professor Peng Lanshuo pointed out in his book "Introduction to Network Communication" that the formation of fragmented communication has a profound era background. If you look into its meaning, one will find that it represents a change in the mode of communication to some extent. Relatively speaking, the value of short videos is to guide traffic and promote brands, and to achieve fragmented communication. The combination of systematic and fragmented communication meets the needs of a wider range of users. In the process of documentary creation, mainstream media should further spread with a civilian attitude, create their own mini-documentary, or even short videos, to create a good image. With the expansion of video platforms, mainstream media should be supplemented with sufficient resources to advertise micro-documentaries, so that microdocumentaries can become a new publicity portal and an important means of national image dissemination. In the process of dissemination, different cultural discourse systems including local and foreign, mainstream and subcultures collide with each other, bringing new possibilities for culture.

\section{INNOVATION AND APPLICATION OF VR VIRTUAL REALITY TECHNOLOGY}

The use of VR technology opens a new window of the future for documentary filming, production and experience. The documentary "Kindergarten in a Mountain Village" carried out 360-degree follow-up shooting and display of leftbehind children in Songtao, Guizhou and Guzhang, Hunan, making their day-to-day scenes appear to be around the audience. In other words, the infinite pursuit of "reality" by VR technology breaks through the limitation of "separation of human and machine" in the traditional documentary watching process, making the audience immersive and realize the spiritual aspirations and lack of characters in the film. VR technology brings a new breeze to the traditional documentary production mode. Theme documentary can also try VR technology. It can connect with narrative language through smooth lens, and use VR technology to construct immersive, interactive and intuitive virtual reality, so that audiences can fully experience the shocking effect that traditional documentaries can't match.

\section{CONCLUSION}

The theme documentary is an expression of the will of the country and has important political communication significance. In the new era, the potential of documentary in political communication will be further explored and released. In these political years, whether it is the construction of mainstream ideology or the image footnotes left for the times, documentaries will not be absent. The mainstream discourse of documentaries has returned, and the political identity of newgeneration documentaries will continue to be strengthened. Whether it is the building of a national image, the construction of mainstream ideology, cross-cultural communication and communication, or the expansion of people's aesthetic education, aesthetic cognition, and aesthetic entertainment, the value and influence of documentaries will continue to manifest. The research on documentaries, especially the main theme works is very meaningful.

\section{REFERENCES}

[1] He Suliu, China Documentary Development Report (2018) [M]. Beijing: Social Sciences Academic Press (China), 2018. (in Chinese)

[2] Liu Zhongbo, Guan Yexin, A Review of Theoretical Research on Chinese Documentary in 2018 [J]. CHINA TELEPAPER, 2019 (2). (in Chinese)

[3] Mi Xinjun. Image Aesthetics and Innovation of Theme Documentary in Multi-New Media Context [J]. Contemporary Cinema, 2019 (5). (in Chinese) 